\title{
THE STEREOCHEMISTRY AND CONFORMATION OF LIGNIN AS JUDGED BY X-RAY CRYSTALLOGRAPHIC INVESTIGATIONS OF LIGNIN MODEL COMPOUNDS: ARYLGLYCEROL $\beta$-GUAIACYL ETHERS
}

\author{
Vratislav Langer, ${ }^{a}$ Knut Lundquist, ${ }^{b^{*}}$ and Jim Parkås ${ }^{\text {b† }}$ \\ The conformations of a variety of crystalline lignin models representing \\ different diastereomeric forms of structural elements in lignin of the \\ arylglycerol $\beta$-guaiacyl ether type have been studied using X-ray \\ crystallography. Based on X-ray crystallographic data, sequences of \\ units attached to each other by $\beta$-guaiacyl ether linkages were \\ constructed. The appearance of the resulting oligomers shows that \\ stereoisomerism can be expected to influence the shape of the lignin \\ molecules to a great extent. The constructed oligomers provide an idea \\ about the contribution to the complexity of lignins by stereochemistry \\ alone. It is proposed that structural differences, together with \\ conformational variations, are the main reasons for the broadness of the \\ signals in NMR spectra of lignins.
}

Keywords: Arylglycerol $\beta$-guaiacyl ethers, Conformation, Crystallography, Lignin

Contact information: a: Environmental Inorganic Chemistry, Department of Chemical and Biological Engineering, Chalmers University of Technology, SE-41296 Göteborg, Sweden; b: Forest Products and Chemical Engineering, Department of Chemical and Biological Engineering, Chalmers University of Technology, SE-41296 Göteborg, Sweden; †: Present address: Södra Cell AB, R\&D, SE-43024 Väröbacka, Sweden; *Corresponding author: knutl@,chalmers.se

\section{INTRODUCTION}

In spite of the polymeric nature of lignins, the peak positions in ${ }^{13} \mathrm{C}$ NMR spectra (Robert 1992) and ${ }^{1} \mathrm{H}$ NMR spectra (Lundquist 1992) of lignins agree very well with those expected from examinations of appropriate low molecular weight model compounds. However, due to superimposition of signals the resolution of the lignin spectra is rather limited. This is related to the irregular and complex structure of lignins. Even signals separated from other signals in the lignin spectra are typically broad, in particular in ${ }^{1} \mathrm{H}$ NMR spectra. The broadness of lignin NMR signals is also reflected in the appearance of 2D NMR spectra (see, e.g., Ralph et al. 2004). We think that not only structural variation but also differences in conformation contribute to the broadness of the signals. The appearance of lignin spectra reflects a regular lignin structure in the sense that lignins consist of phenylpropane units attached to each other by different types of linkages (Adler 1977). Substances completely lacking in structural order, e.g. "humic substances", give rise to almost featureless NMR spectra (Lundquist et al. 1985). It is evident that the stereochemistry and conformation of the lignin molecules are of interest in connection with the interpretation of NMR spectra of lignins. Aiming at an elucidation 
of the stereochemistry and conformation of the lignin molecules, the conformation of a variety of lignin models, representative of different types of lignin structures, was examined by X-ray crystallography (Lundquist et al. 2003). It was found that the bulky aromatic groups in many cases tend to be far apart from each other in the conformations adopted. This suggests that $\pi-\pi$ electron repulsion (Hunter and Sanders 1990) between aromatic groups plays a role. However, it is evident that other factors (e.g. hydrogen bonding) also influence the conformations of the model compounds examined. Chen and Sarkanen (2003) have speculated that charge-transfer complexes cause attraction between aromatic nuclei in lignins. However, the geometrical requirements for such complexes are very precise (Hunter and Sanders 1990). In our opinion they are normally not fulfilled in lignins.

We have paid special attention to model compounds representative of arylglycerol $\beta$-aryl ethers, since such structures represent a major type of structural elements in lignins. Here we have focused on sequences of arylglycerol $\beta$-guaiacyl ethers (Fig. 1). Sequences of such structural elements can be expected to occur rather frequently in lignins, since the number of this type of $\beta$-aryl ethers is large, in particular in softwood lignins (Adler 1977). Lignin degradation products partly consisting of sequences of $\beta$ ethers are known (Nimz 1974). It is noteworthy that Erdtman and Leopold (1949) as early as 1949 speculated about the existence of $\beta$-ether sequences of the topical type within lignin.

\section{MATERIAL AND METHODS}

The threo form of $\mathbf{1}$ was lately obtained in crystalline form, and its crystal structure was determined (Langer and Lundquist, 2002). The crystal structure of the erythro form of 1 has been reported by Stomberg and Lundquist (1994).

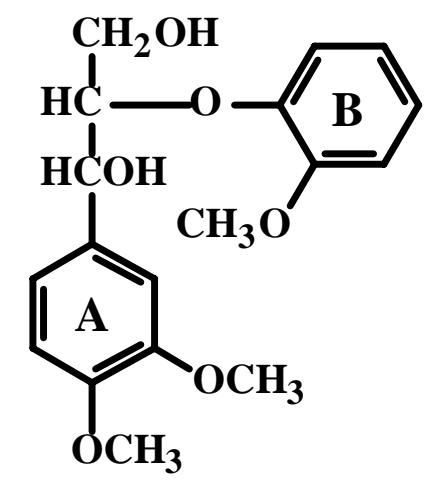

\section{1}

Based on the molecules in the crystal structures, oligomers consisting of structural elements of arylglycerol $\beta$-guaiacyl ether type were constructed digitally. This was accomplished by replacing the guaiacyl groups (e.g. ring B in 1) in the molecules by ring 
A ("demethylated" in the 4-position) in attached molecules of $\mathbf{1}$. The computer work required was carried out using the program MERCURY (Macrae et al. 2006).

MERCURY is a program for visualization and analysis of crystal structures. In its full version, provided to users of the Cambridge Structural Database system, display and overlay of multiple structures as well as editing of molecules is possible. By applying this program to molecules of $\mathbf{1}$ taken from the crystal structures it was possible to construct the oligomers by superimposing the B ring (in $\mathbf{1}$ or in constructed oligomers) with the A ring in 1 , whereupon the $\mathrm{B}$ ring and the $p$-methoxy group in $\mathrm{A}$ was removed. The geometries of the two rings (A and $\mathrm{B}$ ) are almost identical, implying that all the geometrical details of the constructed oligomers are identical or practically identical with those found in the crystal structures. Constructed oligomers are shown in Results and Discussion.

\section{RESULTS AND DISCUSSION}

It is in general assumed that lignins are optically inactive and that the structural elements within lignins are "racemic." The correctness of this assumption has been confirmed in recent studies (Ralph et al. 1999; Akiyama et al. 2000). It is important to recognize that the occurrence of "racemic" structural elements in lignins by no means excludes an uneven distribution of different diastereomeric forms. However, investigations have shown that about equal amounts of the erythro and threo forms of arylglycerol $\beta$-guaiacyl ethers (Fig. 1) are present in lignins (Hauteville et al. 1986; Akiyama et al. 2005).

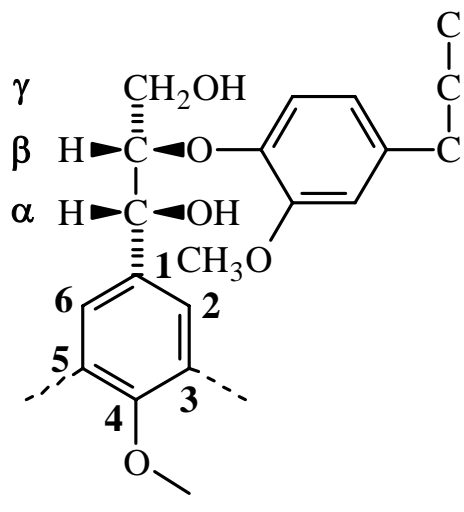

erythro

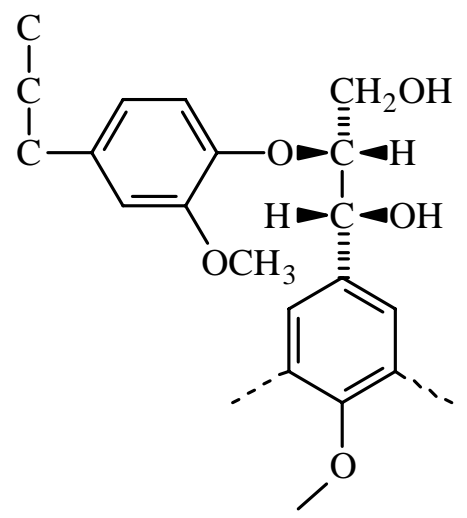

threo

Fig. 1. The erythro $\left(\alpha R^{*}, \beta S^{*}\right)$ and threo $\left(\alpha R^{*}, \beta R^{*}\right)$ forms of arylglycerol $\beta$-guaiacyl ethers.

We have studied the conformational options of such structural elements based on X-ray crystallography of lignin model compounds (Stomberg et al. 1988; Stomberg and Lundquist 1994; Lundquist et al. 1996; Langer and Lundquist 2002). Computational studies constitute an alternative approach to study the conformation of this type of structural elements (Simon and Eriksson 1998; Besombes et al. 2003). The results obtained by the two approaches concur in general (Lundquist et al. 2003). The 
conformation of compounds of the arylglycerol $\beta$-guaiacyl ether type is largely determined by two torsion angles: $\mathrm{C}_{\text {aryl }}-\mathrm{C}_{\alpha}-\mathrm{C}_{\beta}-\mathrm{O}$ and $\mathrm{C}_{\text {aryl }}-\mathrm{O}-\mathrm{C}_{\beta}-\mathrm{C}_{\alpha}$ (Fig. 2).

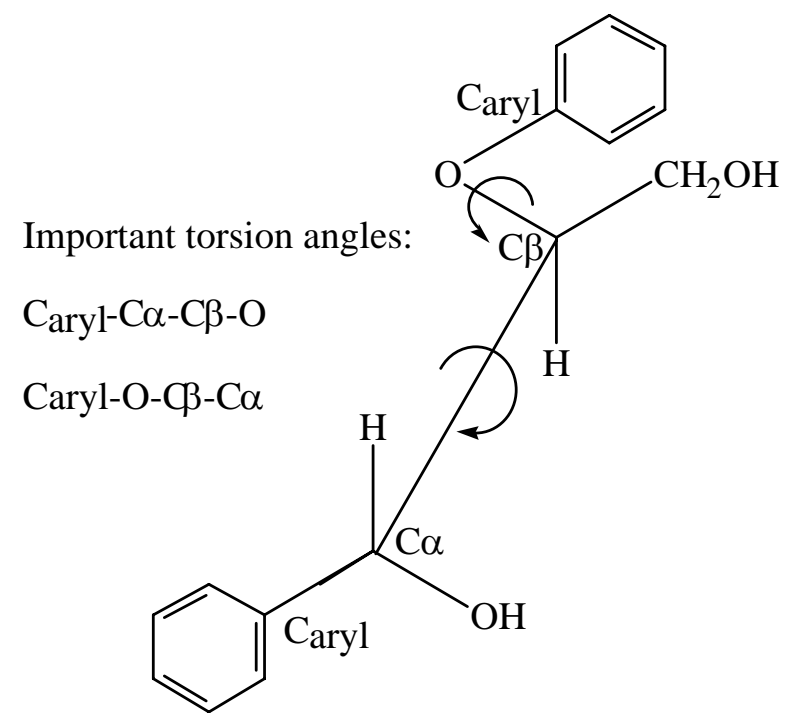

Fig. 2. Torsion angles of importance for the conformation of arylglycerol $\beta$-aryl ethers: $\mathrm{C}_{\text {aryl- }}-\mathrm{C}_{\alpha}-\mathrm{C}_{\beta}$ $\mathrm{O}$ and $\mathrm{C}_{\text {ary }}-\mathrm{O}-\mathrm{C}_{\beta}-\mathrm{C}_{\alpha}$.

In the following discussion of torsion angles we have considered the isomer with $R$-configuration at $\mathrm{C}_{\alpha}$. In all the erythro forms of dimeric lignin models so far examined the $\mathrm{C}_{\text {aryl }}-\mathrm{C}_{\alpha}-\mathrm{C}_{\beta}-\mathrm{O}$ angle is about $60^{\circ}$ and the $\mathrm{C}_{\text {aryl }}-\mathrm{O}-\mathrm{C}_{\beta}-\mathrm{C}_{\alpha}$ angle is about $-140^{\circ}$. A more complex model of erythro $\beta$-guaiacyl ether type adopts a similar conformation (Roblin et al. 2000). In contrast, the $\mathrm{C}_{\text {aryl }}-\mathrm{C}_{\alpha}-\mathrm{C}_{\beta}-\mathrm{O}$ angle is about $180^{\circ}$ in the threo forms examined, while the $\mathrm{C}_{\text {aryl }}-\mathrm{O}-\mathrm{C}_{\beta}-\mathrm{C}_{\alpha}$ angles range from $105^{\circ}$ to $165^{\circ}$. The angle between the aromatic ring planes is also of interest in this context. This angle is fairly large in the compounds examined; the smallest ring plane angle $\left(38^{\circ}\right)$ is found in the rather complex model examined by Roblin et al. (2000). Evidently the examined lignin models adopt similar conformations regardless of structural variation. Therefore we think that the conformational results obtained in model compound studies are applicable to lignin too.

We have constructed sequences of arylglycerol $\beta$-guaiacyl ethers based on different enantiomeric forms of the crystal structures of the erythro and threo forms of 1(3,4-dimethoxyphenyl)-2-(2-methoxyphenoxy)-1,3-propanediol (1) (Stomberg and Lundquist 1994; Langer and Lundquist 2002). The conformations of these compounds are fairly representative for all the other arylglycerol $\beta$-guaiacyl ethers examined, although the $\mathrm{C}_{\text {aryl }}-\mathrm{O}-\mathrm{C}_{\beta}-\mathrm{C}_{\alpha}$ angle in the threo form $\left(165^{\circ}\right)$ is somewhat larger than the corresponding angle in the other threo forms. The constructed oligomers illustrate the influence of stereochemistry on the shape of the lignin molecules. The constructed "lignin models" are representative of segments of lignin molecules, and they should not be viewed as models for individual lignin molecules. Figure 3 shows a series of oligomers constructed by combining X-ray crystallographic data for pairs of the stereoisomeric forms of 1 . The configuration $(R, S)$ of the chiral carbon atoms in the oligomers is shown. The total number of stereoisomers is 16 ( 8 racemates). 

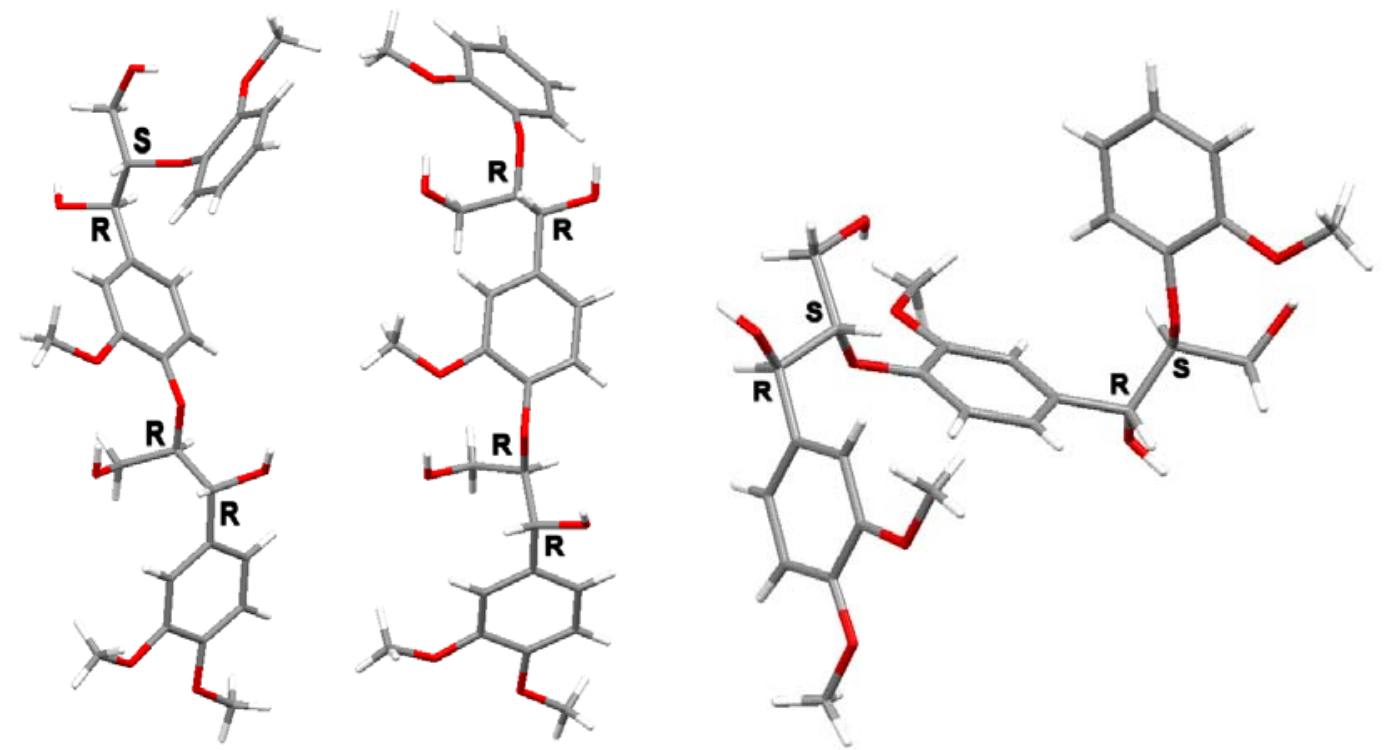

Fig. 3. Examples of stereoisomers of lignin models consisting of sequences of 3 units attached to each other by $\beta$-guaiacyl ether linkages. The mirror images of the compounds constitute additional examples of stereoisomers of the topical lignin models.

The examples in Fig. 3 illustrate the influence of stereochemistry on the shape of the molecules. To further study the influence of stereochemistry on the shape of this type of molecules we have constructed oligomers consisting of five units. In this case there are 256 isomers. Two of the isomers are shown in Fig. 4. The shapes of the two molecules are very different.

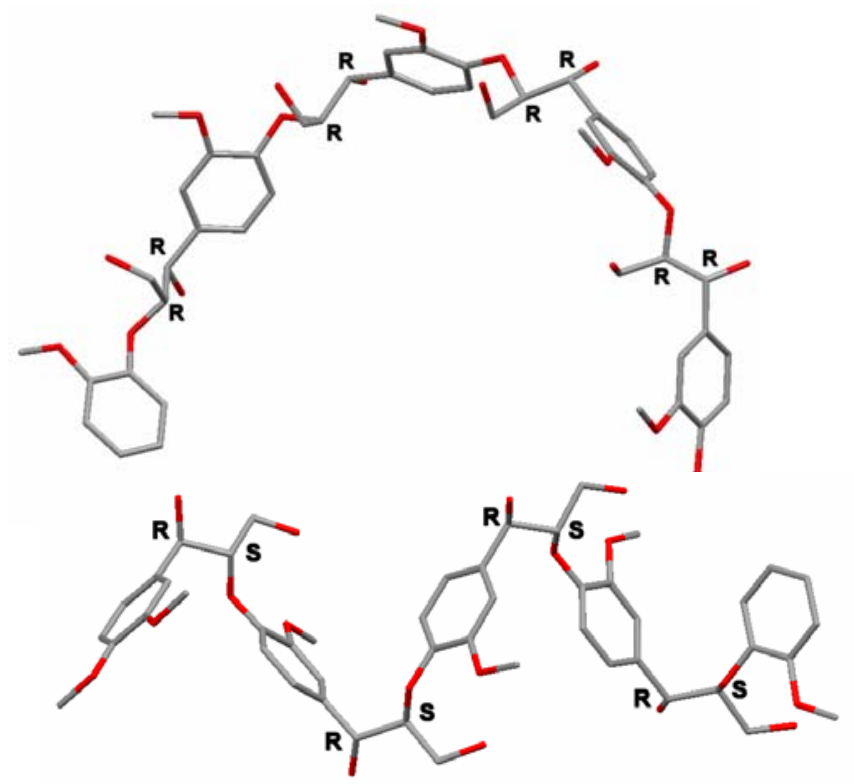

Fig. 4. Examples of stereoisomers of lignin models consisting of sequences of 5 units attached to each other by $\beta$-guaiacyl ether linkages. The mirror images of the compounds constitute additional examples of stereoisomers of the topical lignin models. 
As pointed out above, it is known that lignin is "racemic" and that about equal amounts of erythro and threo forms of arylglycerol $\beta$-guaiacyl ethers are present in lignins. These facts have been considered in the construction of one of the stereoisomers of an oligomer consisting of nine units (Fig. 5). The constructed stereoisomer consists of both enantiomers of two erythro forms and two threo forms of arylglycerol $\beta$-guaiacyl ethers. The total number of isomers is 65536. The discussion of the complexity of the lignin structure in more general terms by Ralph et al. (2004) is of interest in this context.

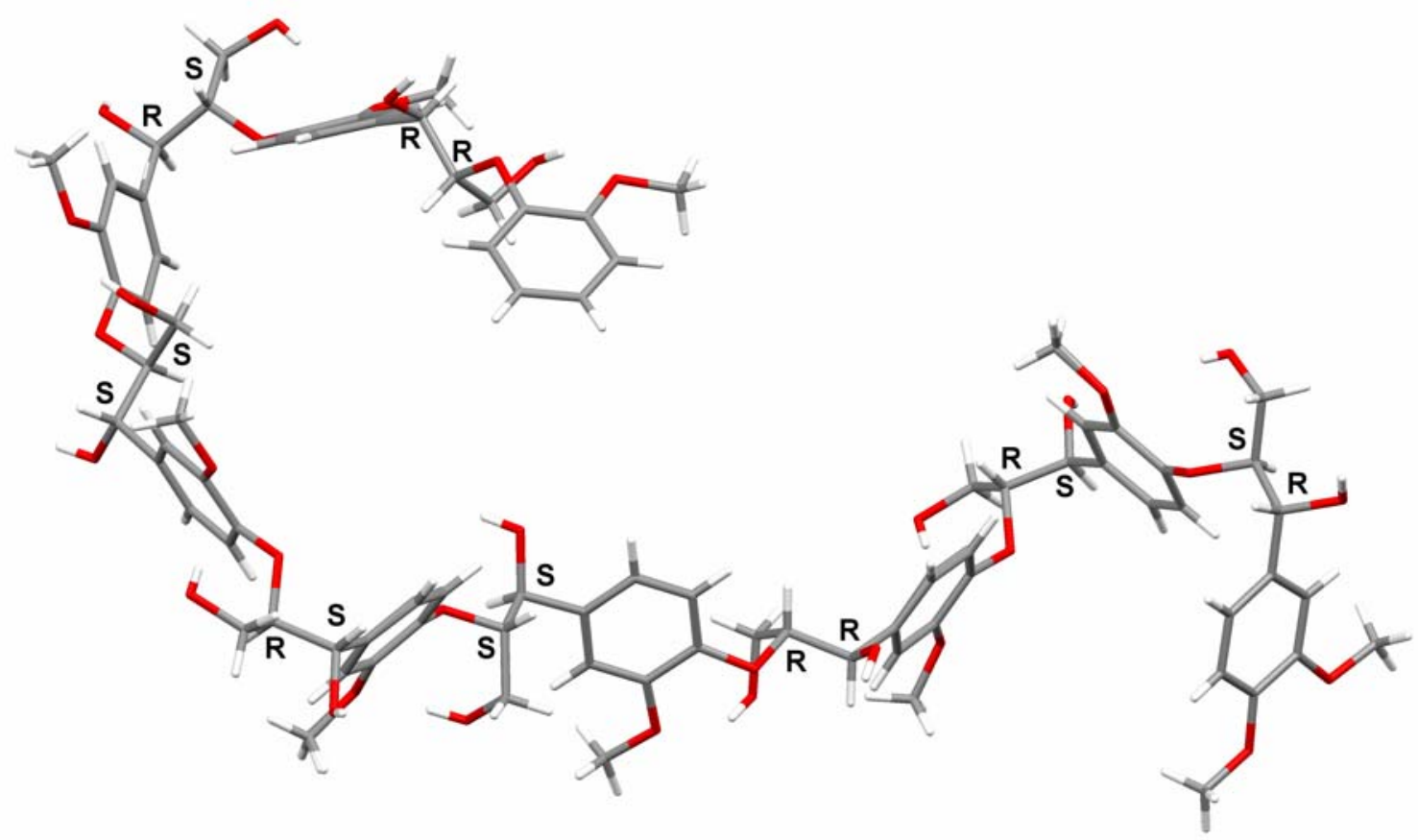

Fig. 5. Stereoisomer of a lignin model consisting of a sequence of 9 units attached to each other by $\beta$-guaiacyl ether linkages. The distribution of enantiomers and diastereomers is representative of what on an average is prevailing in lignins.

It is well known that stereochemistry and conformation influence the positions of NMR signals. Stereochemical and conformational differences result in small changes of chemical shifts (upfield or downfield) of the signals in NMR spectra. The constructed sequences of lignin units discussed in this paper exemplify that there is a considerable diversity with respect to stereochemistry and conformation in lignins. This is consistent with the fact that in spite of the broadness of the lignin NMR signals, the signal positions fit very well with what is expected from examinations of appropriate model compounds.

\section{CONCLUSIONS}

1. Stereochemistry and conformation have a decisive influence on the shape of the lignin molecules. 
2. The sequences of arylglycerol $\beta$-guaiacyl ethers studied exist in a very large number of stereoisomeric forms. This provides an idea about the considerable contribution of stereoisomerism alone to the complexity of the lignin structure.

3. Lignin stereochemistry is of importance in connection with analytical lignin work.

\section{REFERENCES CITED}

Adler, E. (1977). “Lignin chemistry-past, present and future,” J. Wood Chem. Technol. 11(3), 169-218.

Akiyama, T., Magara, K., Matsumoto, Y., Meshitsuka, G., Ishizu, A., and Lundquist, K. (2000). "Proof of the presence of racemic forms of arylglycerol- $\beta$-aryl ether structure in lignin: studies on the stereo structure of lignin by ozonation," J. Wood Sci. 46(5), 414-415.

Akiyama, T., Goto, H., Nawawi, D. S., Syafii, W., Matsumoto, Y., and Meshitsuka, G. (2005). "Erythro/threo ratio of $\beta-\mathrm{O}-4$ structures as an important structural characteristic of lignin. Part 4: Variation in the erythro/threo ratio in softwood and hardwood lignins and its relation to syringyl/guaiacyl ratio," Holzforschung 59(3), 276-281.

Besombes, S., Robert, D., Utille, J.-P., Taravel, F. R., and Mazeau, K. (2003). "Molecular modeling of lignin $\beta$-O-4 model compounds. Comparative study of the computed and experimental conformational properties for a guaiacyl $\beta-\mathrm{O}-4$ dimer," Holzforschung 57(3), 266-274.

Chen, Y.-R., and Sarkanen, S. (2003). "Macromolecular lignin replication: A mechanistic working hypothesis," Phytochem. Rev. 2(3), 235-255.

Erdtman, H. and Leopold, B. (1949). "Aromatic keto- and hydroxy-polyethers as lignin models. II," Acta Chem. Scand. 3(10B), 1358-1378.

Hauteville, M., Lundquist, K., and von Unge, S. (1986). "NMR studies of lignins. (7). 1H NMR spectroscopic investigation of the distribution of erythro and threo forms of $\beta$ O-4 structures in lignins," Acta Chem. Scand. B40(1), 31-35.

Hunter, C. A., and Sanders, J. K. M. (1990). "The nature of $\pi-\pi$ interactions," J. Amer. Chem. Soc. 112(14), 5525-5534.

Langer, V., and Lundquist, K. (2002). "threo-1-(3,4-Dimethoxyphenyl)-2-(2-methoxyphenoxy)-1,3-propanediol,” Acta Cryst. E58(4), o433-0435.

Lundquist, K. (1992). "Proton $\left({ }^{1} \mathrm{H}\right)$ NMR spectroscopy," In: Methods in Lignin Chemistry, S. Y. Lin and C. W. Dence (eds.), Springer-Verlag, Berlin, Germany, 242249.

Lundquist, K., Paxéus, N., Bardet, M., and Robert, D. R. (1985). "Structural Characterization of Aquatic Humic Substances by NMR," Chemica Scripta 25(4), 373-375.

Lundquist, K., Li, S., and Stomberg, R. (1996). "Stereochemistry of lignin structures of the arylglycerol $\beta$-aryl ether type. Crystal structures of the threo form of guaiacylglycerol $\beta$-guaiacyl ether and its triacetate," Nord. Pulp Pap. Res. J. 11(1), 43-47. 
Lundquist, K., Langer, V., Li, S., and Stomberg, R. (2003). "Lignin stereochemistry and its biosynthetic implications," Proc. of the 12th International Symposium on Wood and Pulping Chemistry, Madison, Wisconsin, USA, June 9-12. pp. 239-244.

Macrae, C. F., Edgington, P. R., McCabe, P., Pidcock, E., Shields, G. P., Taylor, R., Towler, M., and van de Streek, J. (2006). "Mercury: visualization and analysis of crystal structures," J. Appl. Cryst. 39(3), 453-457.

Nimz, H. (1974). "Beech lignin - Proposal of a constitutional scheme," Angew. Chem. Internat. Edit. 13(5), 313-321.

Ralph, J., Peng, J., Lu, F., Hatfield, R. D., and Helm, R. F. (1999). “Are lignins optically active?," J. Agric. Food Chem. 47(8), 2991-2996.

Ralph, J., Lundquist, K., Brunow, G., Lu, F., Kim, H., Schatz, P. F., Marita, J. M., Hatfield, R., Ralph, S. A., Christensen, J. H., and Boerjan, W. (2004): "Lignins: Natural polymers from oxidative coupling of 4-hydroxyphenylpropanoids," Phytochem. Rev. 3(1-2), 29-60.

Robert, D. (1992). "Carbon-13 nuclear magnetic resonance spectroscopy," In: Methods in Lignin Chemistry, S. Y. Lin and C. W. Dence (eds.), Springer-Verlag, Berlin, Germany, 250-273.

Roblin, J.-P., Duran, H., Duran, E., Gorrichon, L., and Donnadieu, B. (2000). 'X-ray structure of a trimeric 5,5'-biaryl/erythro- $\beta$-O-4-ether lignin model: Evidence for through-space weak interactions," Chem. Eur. J. 6(7), 1229-1235.

Simon, J. P., and Eriksson, K.-E. L. (1998). "Computational studies of the threedimensional structure of guaiacyl $\beta$-O-4 lignin models," Holzforschung 52(3), 287296.

Stomberg, R., Hauteville, M., and Lundquist, K. (1988). "Studies on lignin model compounds of the $\beta$-O-4 type: crystal structure of threo-1-(4-hydroxy-3,5dimethoxyphenyl)-2-(2-methoxyphenoxy)-1,3-propanediol and 3-hydroxy-1-(4hydroxy-3,5-dimethoxyphenyl)-2-(2-methoxyphenoxy)-1-propanone-methanol (1/1)," Acta Chem. Scand. Ser. B 42(10), 697-707.

Stomberg, R., and Lundquist, K. (1994). "Stereochemistry of lignin structures of the $\beta$-O4 type. Crystal structures of model compounds," Nord. Pulp Pap. Res. J. 9(1), 37-43.

Article submitted: Sept. 9, 2007; First round of peer-review completed: Oct. 10, 2007; Revised version received and accepted: Oct. 15, 2007; Article published: Oct. 16, 2007. 